\title{
Legal status of pharmaceutical industry secrecy In the UAE legal system
}

\author{
Dr. Jihad Saleh Bani Younes \\ College of Law, American University in the Emirates
}

\begin{abstract}
Facing the problem of matching growth and status, starting work, starting work, starting work, starting work, starting work, starting work, starting work, and the United Arab Emirates. This harmonization - by approving a set of exceptions of this nature has some of the effects and the secret idea behind it.

As we see him, he relied on the idea of public order in order to set some exceptions related to the inventions themselves by excluding some of them from the requirement to obtain a patent certificate, which is stipulated in Article 6 of the Law on the Organization and Protection of Industrial Property, and he also made exceptions related to the rights established for the inventor, which are It gives him the power to monopolize and dominate the invention if the inventor has what is in conflict with the objectives of scientific research, which is stipulated in Article 19 of the aforementioned law, and we see that the UAE legislator has organized the idea of compulsory licensing contracts for pharmaceutical products in accordance with the interests of both the licensee and the licensee. Both.

Research problem: considering that the pharmaceutical industry in the UAE is a strategic industry, and because of the fluctuation of drug prices in the global and local market. Therefore, the problem of this research will focus not on the extent to which the pharmaceutical industry in the Emirates can activate its role in the UAE national economy in light of the UAE pharmaceutical legislation, and whether these legislations were able to create a balance between secrecy in the pharmaceutical industry and scientific progress in this industry.

research assumes:

1- There is no relationship between advances in the pharmaceutical industry in the UAE and the confidentiality imposed by the TRIPS Agreement.

2- The UAE's accession to the TRIPS Agreement had a negative impact on the pharmaceutical industry.

3- The Emirati legislator was able to create a consensus between commitment to confidentiality and the manufacture of medicines. research aims:

1 - Introducing confidentiality in the pharmaceutical industry.

2- Identifying the main obstacles to the pharmaceutical industry in the UAE.

3- Developing proposals to activate the role of local legislation to create a balance between confidentiality and the pharmaceutical industry.

research importance:

The importance of the research lies in focusing on the balance between confidentiality and the local pharmaceutical industry to have a developmental role. Thus, we will try to reveal the state of the pharmaceutical industry in the UAE. And how to stimulate the pharmaceutical industry through national legislation

Research methodology: The researcher will rely on a descriptive approach to analyze and characterize the special industrial reality in medicine in the UAE and analyze private legislation

Based on the foregoing, and in order to understand the position of the Emirati legislator on the idea of secrecy in the pharmaceutical industries more, this requirement must be divided into two studies. In the first, we review the concept of confidentiality in the pharmaceutical industries. Second: the concerted attempts to mitigate the negative effects of confidentiality in the pharmaceutical industries.
\end{abstract}

Article Received: 18 October 2020, Revised: 3 November 2020, Accepted: 24 December 2020

\section{The first topic}

The concept of secrecy in the pharmaceutical industries

It goes without saying that the secrecy of any system that brings the owners of this system the required security, which will benefit it and ensure that it gets all the financial returns from this system that it owns and that results from its marketing and sale without fear of violating it, assaulting it, or selling it on the black markets and thus negatively 
affecting it. On sales volume and thus negatively affecting profit margins and returns

In order to get acquainted with the concept of confidentiality in the pharmaceutical industries, it is first necessary to clarify what is meant by confidentiality in international industries according to the position of the Emirati legislator, and then determine when the information is considered confidential and thus the duty to protect and prevent others from disclosing it, and for this we will divide this topic into two requirements. We devote the second to defining the conditions for considering undisclosed information as confidential and therefore a duty to protect, as follows:

\section{The first requirement}

\section{What is confidentiality}

Others think that what is meant is "all confidential information related to a certain commodity or products, including innovations, formulations, components, elements, methods, methods, or industrial means, and as a whole it is a group of technical and technological knowledge and trade secrets related to the goods and products that the product keeps." Or the manufacturer and did not disclose it. "

The International Organization for Standardization (ISO) defines it in ISO 17799 as "ensuring that information is available only to those who are authorized to view" and this organization considers it one of the main pillars of information security. ${ }^{1}$ The International Organization for Standardization (ISO) defines it in ISO 17799 as "ensuring that information is available only to those who are authorized to view" and this organization considers it one of the main pillars of information security. ${ }^{2}$

The Emirati legislator did not address the enactment of a law on trade secrets or undisclosed information, but we find that in Article 64 of the Commercial Transactions Law No. 18 of 1993 regarding commercial transactions, it is considered

\footnotetext{
${ }^{1}$ Linguistic exercises in grammar, morphology, and common errors - Mustafa Abdul Aziz Al-Sanjerji

${ }^{2}$ Ahmed Youssef Ahmed: Future Economic Cooperation and Future Prospects, The Arab Foundation for Studies and Publishing, Beirut, Lebanon, 2001.
}

that the person's acquaintance with the secrets of his commercial competitor is considered an act of unfair competition, which must be held accountable. Civil and compensation claim ${ }^{3}$

It may seem to some that the position of the previous Emirati legislator indicates that there is no legal regulation of confidential information within the UAE legal system, but this belief is incorrect, when we know that the UAE is one of the first countries to join the agreement to establish the World Trade Organization and thus adhere to all its annexes. And the agreements that resulted from it, including the (TRIPS) agreement. Before that, the United Arab Emirates was considered one of the first Arab countries to join the Paris Convention for the Protection of Industrial Property of 1886 (Stockholm amendment of 07/14/1967),

According to the foregoing, we find that the international approach represented by the Paris Convention for the Protection of Industrial Property and the TRIPS Agreement, which together constitute the legal position of the UAE regarding the idea of confidentiality, prohibiting any act of unfair competition on any information that is not disclosed or confidential in nature, It is also prohibited to divulge any data provided to governments or government agencies, as follows:

\section{First branch}

\section{Undisclosed information}

The Paris Agreement gave the person - whether natural or legal - the absolute right to prevent others from disclosing or disclosing any information that they possess legally or were able to obtain it, as well as preventing others from using this information without obtaining the prior consent of its owner, provided that it is This information is confidential in nature.

In the context of determining what is meant by secret information in this regard, we find that it is "all information related to a certain commodity or products, including innovations, formulations,

\footnotetext{
${ }^{3}$ Edwin Mansfield: Applied Economics in Business Administration, translated by George Fahmy Rizk, Academic Library, Cairo, Egypt
} 
components, elements, methods, methods or industrial means, and in general it is a group of technical and technological knowledge and trade secrets." Related to the goods and products that the producer or manufacturer keeps and has not disclosed. ${ }^{4}$

And the meaning of confidentiality, which was defined by the Paris Agreement and taken by the Emirati legislator as it is, does not differ much in terms of the meaning of secrecy in American law as a condition for protecting trade secrets, because what is meant by confidentiality in the said agreement is relative secrecy and not absolute secrecy, meaning that the information holder discloses about it to a number Few persons, such as workers in the drug company or partners, do not lead to the loss of confidentiality of information as long as there is an obligation on those who disclose this information to them not to disclose it to others ${ }^{5}$ We conclude that the condition of confidentiality of undisclosed information means, in short, not to access this information easily or by illegal means by other than its owners.

The Paris Agreement made it clear that the violation of disclosure of undisclosed information may take place in one of the following ways:

- Carrying out any act that is considered in the eyes of the law as acts of unfair commercial competition by violating the terms and conditions of the contract or violating the confidential nature of this information entrusted with it.

- Obtaining the undisclosed information through gross negligence of the scientist who owns this information. Bribery of employees of the entity that possesses the information in order to obtain it

- Incitement to divulge information on the part of workers if that information has reached their work by virtue of their job.

\footnotetext{
${ }^{4} 4 \mathrm{Mr}$. Ahmed Abdel Khaleq: Protection of Intellectual Property Rights under the TRIPS Agreement and Economic Legislation, First Edition, House of Thought and Law, Alexandria, Egypt, 2011.

Biha Geratlal Das: World Trade Organization Agreements, "Defects, Imbalances, and Necessary Changes", Dar AlMerrekh, Riyadh, Kingdom of Saudi Arabia, 2005.
}

- One of the contracting parties in the licensing contracts to exploit the confidentiality of information discloses what he knew about it

- Obtaining undisclosed information from places where it is kept, illegally or fraudulently ${ }^{6}$

\section{The second branch}

\section{Data provided to government agencies}

The Paris Agreement requires its member states, which stipulates in order to allow the marketing of medicinal preparations and agricultural-chemical materials in which new chemical components are used, to submit documents that include test results (test data), whether these data relate to chemical substances. Or biological materials for these new chemical components, and to provide the necessary protection for these test data from the risk of any unfair or unjust commercial use, including protection from the risk of disclosing them to the public except in the case of necessity, provided:

- That this data is by nature confidential and not disclosed to the public.

- That this data, by its nature, be the result of hard, painstaking and monumental work.

- You are the party that owns this data and has made enough effort to consider it confidential and thus sufficient to protect it from the risk of unjust commercial use.

\section{The second requirement Confidentiality conditions}

In accordance with the provisions of the Paris Agreement and the TRIPS Agreement, which is the position in force in the United Arab Emirates, in order for the information to be considered confidential and thus eligible for legal protection against any practice that may lead to its disclosure, access to it, or the use of it without the permission of its owner, this is required The information itself is confidential, and it has a commercial value that

\footnotetext{
${ }^{5} 7$ / Jalal Wafa Muhammadin: Legal Protection of Industrial Property According to the Agreement on Trade Related Aspects of Intellectual Property Rights (TRIPS), New University Publishing House, Egypt, 2000 ${ }^{6}$ Hossam El Din Abdel Ghan El Sagheer: Foundations and Principles of the Agreement on Trade-Related Aspects of Intellectual Property Rights "The TRIPS Agreement", First Edition, Arab Renaissance House, Cairo, 1999
} 
is an addition to it, and that its owner has made enough measures to consider it confidential and permanent as well, and for this we will divide this requirement into three branches, and in each of them we review the three conditions mentioned above, as follows: next one:

\section{First branch}

\section{secrecy}

The TRIPS Agreement required that information be confidential given that whether in its entirety, in its final form, method of manufacture, or method of assembling its components, information is unknown and unavailable to the knowledge of the concerned public, which is the group of its dealers. It follows from this condition through the stipulation of the said agreement that this information - which may be in the form of a statement or an image of an idea - is unknown by anyone, whether in terms of its precise components or in terms of its form.

Confidentiality, according to what was defined by the Paris Agreement and which was adopted in the TRIPS Agreement, may sometimes be expressed through undisclosed information, which is what was taken by the vast majority of legislators in most countries, including the United Arab Emirates, and may also be expressed in Trade Secrets, which is what It was taken by the American legislator.

The researcher can define secrecy as: not to disclose commercial, industrial, technical or other information in the field of specialization to others in a way that may suggest that its owner is not keen on keeping it hidden and confidential, which gives him an appropriate position distinct from other competitors.

\section{The second branch}

\section{Added commercial value}

The existence of this condition necessitated the practical reality and the natural course of affairs, as if this information was of little or little value, or did not constitute any value added to the financial

\footnotetext{
${ }^{7}$ Essam Malek Ahmed Al-Absi: Compulsory License to Exploit the Patent, First Edition, Al-Wafa Legal Library, Alexandria, Egypt, 2011
}

liability of its owner, it would not necessarily be secret or undisclosed, and therefore legal protection would not have been eligible as it is confidential and relevant. Influential value for its owner. $^{7}$

The researcher believes that the focus of protection of undisclosed information lies in its confidentiality, and the added value of the information also lies in the sustainability of this confidentiality. Thus, it is easy to reach it, whether in its final form or with its precise components, it loses its added value, which makes it lose the legal protection requirement.

\section{The third branch}

\section{The necessary measures to keep the information confidential}

This condition is achieved for the owner of the information to take a set of measures necessary to maintain and maintain the confidentiality of the information and ensure that it is not reached by the concerned public, for example what the soft drink giant American PepsiCo does in order to preserve the confidentiality of the special and distinctive mixture of its famous soft drink Where you put this recipe or secret mixture inside an iron safe at an American bank, so that no one is allowed to view it except for two people who are not known to the public and who do not travel together on the same flight or on the same plane. ${ }^{8}$

It is known that the person who has the competence to decide on the issue of the availability of the condition of reasonable measures to maintain the confidentiality of undisclosed information is the subject judge who has the right to decide on this issue, provided that the burden of proving the confidentiality of the information rests with the owner of it as he claims to contradict the apparent or ordinary matters. For the sake of this proof, he has the right to conduct all means of proof, considering that the issue of confidentiality here is one of the real issues that may be proven by all

\footnotetext{
${ }^{8}$ Mohamed Hossam Mahmoud Lotfi: Effects of the Agreement on Trade Related Aspects of Intellectual Property Rights (TRIPS) on the legislation of developing countries, Arab Renaissance House, Cairo, Egypt, 2000
} 
methods of proof, including the testimony of witnesses and evidence.

\section{The second topic}

Concerted attempts to mitigate the negative effects of confidentiality in the pharmaceutical industry

In order for us to study the attempts to reduce the arbitrariness of the confidentiality regime in international industries, I must evaluate this system to find out its advantages and identify its shortcomings, and thus facilitate the process of mitigating the severity of this system. Therefore, we review two requests to evaluate the idea of confidentiality in the pharmaceutical industries, and then review the attempts The agreement is to reduce the severity of the confidentiality regime in the pharmaceutical industries through some of the principles of the agreement stipulated in the TRIPS Agreement, which can benefit all member states of this agreement, especially developing countries.

\section{Requirement}

\section{Evaluating the idea of confidentiality in the pharmaceutical industry}

Knowing the effect of secrecy in the pharmaceutical industries is reached through reviewing the defects and advantages of this idea itself, and therefore we will divide this requirement into two branches, in the first of which we review the advantages of the idea of confidentiality, provided that we dedicate the second branch to review the defects of the idea of secrecy, as follows:

\section{First branch}

\section{Confidentiality advantages}

Among the things agreed upon is that the secrecy of any system or idea must provide its owners with the required security, which will benefit him and ensure that he obtains all financial returns from this system that he owns and that results from its marketing and sale without fear of violating it or

\footnotetext{
${ }^{9} 20$ / Nazih Muhammad Al-Sadiq Mahdi: Research entitled "Mechanism for the Protection of Intellectual Property Rights", presented at the Conference on Legal and Economic Aspects of World Trade Organization
}

assaulting it or selling it on the black markets Thus, the negative impact on sales volume, and thus also the negative impact on profit margins and returns. And confidentiality in the medicinal product is considered - rightly - the reason for providing optimum protection for this drug, whether in the stage of production, the stage of marketing or the stage of its sale, and therefore the owner of this drug is in safety, reassurance and peace of mind, as his product is legally protected against disclosure or abuse, whether at the stage Manufacturing or the stage of marketing it and putting it on the market as a final product, which leads to preserving the interests of both the producer and the consumer alike, not only that, but that secrecy guarantees the achievement of scientific benefits and benefits for the medicinal product itself by preserving its micro biological components and preventing their leakage to the public ${ }^{9}$

The secret achieves great economic benefits, whether for the manufacturer, the importing company, or the customer who deals with the sale of medicine in a retail system, because secrecy in the pharmaceutical industries has created a system for trading these industries that has very large financial, scientific and economic returns, namely, the system of compulsory and optional licenses concluded between a product The drug wishing to obtain this drug and the owner of the pharmaceutical patent, and the licensing system in its two forms leads to the circulation and transfer of technology and knowledge and the significant financial returns and remittances it entails in hard currency, which in itself constitutes an item of economic development and the intertwining of the market opening and the flow of commercial movement and creation Job opportunities, not to mention marketing, recruitment of experts, employment and investment stimulation and encouragement ${ }^{10}$ In the field of pharmaceutical industries, all these economic gains would not have

Agreements, UAE University, College of Sharia and Law, Volume One, First Edition, Part 02, Deb, 2005.

${ }^{10}$ Kadoum Mohamed: Research entitled "The Effectiveness of the TRIPS Agreement in the Protection of Intellectual Property Rights", presented in a presentation at the 
been achieved without the drug confidentiality system, as it is self-evident that no licensing contracts are concluded either in their optional form or in their compulsory form if the drugs subject to these licenses were available and known by everyone.

\section{The second branch \\ Confidentiality defects}

Despite the advantages of the idea of secrecy in the pharmaceutical industries, this is not sufficient to prevent it from being exposed to some aspects of criticism because it contains some defects, which we mention in the following:

- That the idea of confidentiality in the pharmaceutical industries is reached through bilateral or multilateral agreements or through licensing contracts for use that are concluded between the producer and the owner of the drug and the customer wishing to obtain this drug, whether it is a private company or one of the state governmental institutions, and these agreements or those Contracts are not devoid of a clause that expressly states a confidentiality clause that imposes an obligation to maintain the confidentiality of information related to this drug,

- The confidentiality of the drug implies a very great practical and marketing difficulty, represented in the fact that the drug manufacturing company carries out this manufacture at the request of each individual client who requests this drug to be in accordance with its specifications and standards, and therefore, fearing disclosure of the drug confidentiality, the manufacturer will have to manufacture This medicine is used repeatedly and according to the customer's requests, specifications and standards, which means that this company should spend more time, effort and money in order to ensure confidentiality and non-disclosure. .

- The researcher believes that the secrecy of the drug is the reason for its high price, which constitutes a great financial burden on the client, whether it is a private company, institution or government body, and there are many facts that indicate that the high price of medicines was the direct reason for the client's inability to acquire them and provide them to the needy. It has, especially in developing and poor countries, due to the monopoly of large companies in production and preventing small companies from benefiting from drug industry technology, as the drug manufacturer often adds a margin of profit to the original price of the drug in order to cover the possibility of this drug being exposed to the risk of disclosure or abuse, whether During its manufacture, marketing, or even after its sale, either by the customer himself or by any other person, whether from the client's employees or from others Either add this margin, so the factory hopes to recover part of its expected loss and avoid falling into a loss that may lead to financial and economic shocks or catastrophes that may lead to it, as it is irreversible as a result of the disclosure of the drug's secret and for this you add a margin of profit on its original price, which naConfidentiality in the pharmaceutical industries constitutes a major obstacle to scientific and technical progress, not to mention that it is considered as a constraint that hinders the flow of trade and the circulation of technology transfer contracts between countries, since scientific and technical progress depends mainly on simulating previous experiences and working on their pattern and development, which is This presupposes knowledge and knowledge of the content of these experiments and those industries and technologies, which we see is not achieved with the condition of secrecy that characterizes the pharmaceutical industriesturally leads to an increase Its price. That is why we may not exaggerate if we say that the pharmaceutical industry becomes the largest sector in terms of revenues for reservations regarding access, disclosure and mutual simulation, and it is at the same time the highest sector regarding confinement and ambiguity, which negatively affects the field of scientific and technical progress 
and greatly reduces the movement of technology transfer.

\section{The second requirement}

\section{The position of the UAE legislator on the idea of} secrecy in the pharmaceutical industry

\section{(Attempts to mitigate this idea)}

In order to clarify the position of the Emirati legislator on the idea of secrecy in the pharmaceutical industries more, this requirement must be divided into three branches. In the first, we review: the position of the Emirati legislator on the idea of the exclusive rights established for the inventor and its relationship to the idea of confidentiality by reducing the concept of the idea of bullying and exclusivity decided for the inventor (research Al-Alami), including how the Emirati legislator was able to limit the negative effects of the idea of drug confidentiality by excluding the requirement to obtain an official patent certificate if the granting of the patent for these inventions affects the higher interests of the state (the idea of public order), provided that we review in the second: Confidentiality and exclusive rights. And the third: confidentiality and compulsory licenses

\section{First branch}

\section{Confidentiality and public order}

We find that the TRIPS Agreement has general jurisdiction in everything related to intellectual property, including of course inventions, which allowed each of its member states to exclude some inventions from the requirement to obtain a patent if it comes to medicine, diagnosis, treatment method or exploitation of microorganisms in the installation or manufacture Some medicines, based on the idea that these medicines are in conflict with the health and therapeutic interest of the state's nationals and therefore are considered inconsistent with the idea of public order within the state and therefore the state in this case may exclude these inventions from the framework of registration and obtaining a patent. Exceeding the confidentiality requirement, which leads to reducing its severity with regard to access and disclosure of the components of this medicine, and even enabling some local drug companies to manufacture the same medicine without this constituting an infringement or violation of intellectual property rights or disclosure of confidentiality.

Under this exception, the Emirati legislator can exclude any inventions related to the health and safety of human life, such as those related to human body cells, human blood and human protein, as well as hormones, genes, and cloning processes. It can also exclude the requirement to obtain a patent for all inventions related to diagnostic, treatment and surgical methods needed to treat humans or animals. As well as all inventions related to plants and animals and mostly biological methods for the production of plants or animals other than nonbiological and microbiological methods and methods.

\section{The second branch}

\section{Confidentiality and exclusive rights}

What concerns us here is the first exception without the second, on which we decide based on that any use, use or import of the drug - the subject matter of protection according to the origin - in any field of scientific research, training or teaching is not considered an infringement of the exclusive rights established for the inventor, and therefore he cannot The inventor prohibits any person from others from using, using, selling, offering for sale or importing any medicine if the purpose of these practices or the achievement of scientific research, whether in schools, universities or specialized centers in hospitals or pharmaceutical factories.

From the above, we conclude to a set of results, perhaps the most important of which are: Information in general in the intellectual property environment can only be protected through the patent system and the undisclosed information system. If it is not capable of being an invention, then the Law on Protection of Undisclosed Information is the law that protects it.

- It is decided that the patent protection system and the undisclosed information protection system are two systems that are not differentiated between 
them, but rather they are complementary to provide a legal protection cover for information in general. In practice, the pharmaceutical industries are liable to be an invention, whether in the manufacturing stage or in the final product stage, provided that these industries involve novelty, industrial viability, and an innovative step.

- The TRIPS Agreement has imposed on the member states to adopt the principle of national treatment with regard to dealing with the invention, and therefore the receiving countries of medicines must be equal in their legal dealings with imported medicines and their treatment of national medicines.

The UAE legislator has regulated the provisions for undisclosed information through the rules and provisions of the TRIPS Agreement, which is related to the provisions of the Paris Convention for the Protection of Industrial Property, which the UAE has joined and ratified and thus is considered part of the internal legal fabric of the state.

- The secrecy system and its severity and strictness have led to directing the Arab pharmaceutical industries towards the manufacture of public domain drugs and common medicines only, and therefore our pharmaceutical industry is not considered a pioneering industry in this field, but rather it is the recycling of what was previously manufactured, which leads to the depletion of more effort, fatigue and money. .

\section{Recommendations:}

1- Working on developing the state's technological capacity to meet the challenge of compulsory licenses so that the state becomes able to manufacture the licensed medicine to use it in a manner comparable to the original product of this medicine, by establishing a research center and specialized laboratories and providing them with qualified human cadres.

2- Working on issuing national legislation related to the regulation of pharmaceutical industries that clarifies its provisions and rules due to the specificity that these industries enjoy and their need for specialized legislation that links with both the texts of the TRIPS Agreement, the Paris Agreement and Law No. 17 of 2000 regarding the regulation and protection of industrial property for patents, brands and industrial models.

3- Adopting the idea of public order to maintain the compatibility between the basic human need for medicine and treatment and the need for the drug manufacturer to profit and reap abundant money, and give priority to human interests in all assumptions and not to yield to the greed of medicine companies and their dishonorable monopoly on medicine.

4- Activating the idea of parallel economy and reverse engineering, although it is one of the hidden economics vocabulary to overcome the greed of drug manufacturers and to achieve the human desire to obtain medicine at reasonable and reasonable prices.

\section{References}

[1] TRIPS Agreement, available at Website: http: // www.gccpo.org/conve/Trips.pdf

[2] The Paris Convention for the Protection of Industrial Property, which was concluded in 1883 in Paris, was completed It was amended on 06 May, the last of which was in 1967.

[3] The Berne Convention for the Protection of Literary and Artistic Works, concluded in 1986 in Switzerland.

[4] The Doha Declaration: issued on $11 / 14 / 2001$ to the World Trade Organization, available at: http://ar.wikipedia.org/wiki.

\section{$B$ - List of references in Arabic:}

[5] Ibrahim Al-Essawi: Al-Ghat and its Sisters, Center for Arab Unity Studies, Third Edition, Beirut, Lebanon, 2001.

[6] Ahmed Yusef Ahmed: Future Economic Cooperation and Future Prospects, The Arab Foundation for Studies and Publishing, Beirut, Lebanon, 2001.

[7] Edwin Mansfield: Applied Economics in Business Administration, translated by 
George Fahmy Rizk, Academic Library, Cairo, Egypt.

[8] Mr. Ahmed Abdel-Khaleq: Protection of intellectual property rights in light of the TRIPS Agreement and legislation AlEqtisadiah, First Edition, House of Thought and Law, Alexandria, Egypt, 2011.

[9] Biha Girathlal Das: World Trade Organization Agreements, "Flaws, Imbalances, and Necessary Changes", Dar Al-Merrekh, Riyadh, Kingdom of Saudi Arabia, 2005.

[10] Jalal Ahmad Khalil: The Legal System for the Protection of Inventions and Transfer of Technology to Developing Countries, Kuwait University Publications, First Edition, 1989.

\section{Electronic references:}

[11] Ahmad Muhammad Faraj Qasim: Constituents and obstacles to Arab economic integration and proposals for its revival, an article published on the website: http://kenanaonline.com/users/AMFK/post s/389972

[12] Suha Halasa: Negative repercussions of WTO on the Jordanian pharmaceutical industry have reduced the ability of developing countries to keep pace with modern technology, an article published on the site:http://:http://www.addustour.com.

[13] Abd al-Rahman Tishuri - Arab Economic Integration in the Face of Challenges, an article published on the site: http://www.ahewar.org/debat/show.art.asp ?aid $=49663$ 